\title{
ACOMPAÑAMIENTO INTEGRAL A VÍCTIMAS \\ DE LA VIOLENCIA POLÍTICA EN COLOMBIA. EL CASO DE LA ESCUELA DE FORMACIÓN POLÍTICA CON POBLACIÓN EN SITUACIÓN DE DESPLAZAMIENTO FORZADO EN CALI
}

\author{
Alexander Castaño Pérez ${ }^{* *}$ \\ David Fernando Erazo Ayerbe***
}

"La organización nos permite tener conocimiento de causa, por eso nosotros debemos trabajar porque esa gente que esta en nuestras organizaciones como individuos conozcan la realidad en la que estamos y que verdaderamente actúen como sujetos políticos, pero ello requiere de acompañamiento para que estos espacios de formación sean efectivos al interior de nuestras organizaciones".

Alba Nancy (Participante de la escuela)

\section{Resumen}

En el presente artículo se discute el desplazamiento forzado como una expresión y estrategia de guerra que, premeditada y preconcebida, logra desestructurar los universos materiales, simbólicos y culturales de la población que es afectada por los órdenes de facto impuestos desde las acciones de guerra de los distintos actores en conflicto. De esta manera, se concibe y se reivindica a la población en situación de desplazamiento forzado en su condición de víctima, pues son unos terceros quienes han infringido daños

*Artículo tipo 2: de Reflexión. El presente artículo es producto de las reflexiones suscitadas en el marco de la sistematización de experiencias respecto a la estrategia de acompañamiento Escuela de Formación Política para Miembros de Organizaciones de Personas en Situación de Desplazamiento (Cali - 2007). Fue presentado en el foro sobre experiencias de aprendizaje a acompañamiento a víctimas de violencia política en el suroccidente colombiano, organizado por la Corporación AVRE en Cali, mayo 2008.

** Trabajador Social (Universidad del Valle). Miembro del grupo de investigación Sujetos y Acciones Colectivas, de la Escuela de Trabajo Social y Desarrollo Humano. alexcape@yahoo.com

*** Trabajador Social (Universidad del Valle). Especialista en teorías, métodos y técnicas de investigación social (Universidad del Valle). Miembro del grupo de investigación Sujetos y Acciones Colectivas, de la Escuela de Trabajo Social y Desarrollo Humano. Profesor Catedrático de la Escuela de la Universidad del Valle. Acompaña procesos de investigación e intervención en derechos humanos con el Proceso de Comunidades Negras (PCN) - Palenque Regional El Congal (Buenaventura). daferazo@yahoo.es. 
profundos en su devenir histórico, pero no por ello esta población pierde su potencialidad como sujeto activo (individual y colectivo) de la reorientación de su propia existencia, por cuanto el centro de su reivindicación debe girar en torno al derecho a la reparación, la justicia y la verdad.

En este sentido, se reflexiona desde una experiencia de intervención concreta (la estrategia escuela de formación política), sobre las características de un acompañamiento psicosocial, caracterizado por la continuidad, desde sus procesos y dinámicas cotidianas de vida, bajo la premisa de generar la práctica habitual de juntarse, organizarse, sin desconocer la presencia de los conflictos propios que subyacen a estos procesos colectivos, pero superponiendo la definición de intereses colectivos, con todas las contradicciones y obstáculos que ello implica.

Palabras clave: Desplazamiento forzado, daño, acompañamiento psicosocial.

\section{Abstract}

In this article discusses the forced displacement as a speech and war strategy that premeditated and pre-been destroy universes materials, symbolic and cultural rights of the population is affected by the de facto orders imposed from the warfare of the various actors in conflict. In this way, was conceived and is claimed to the people in a situation of forced displacement in their victim status, as are some others who have infringed damage deep in its evolution, but not why these people lost their potential as active (individual and collective) of the refocusing of its own existence, as the center of his claim centered right to reparation, justice and truth.

In this sense, it reflects experience from a specific intervention (the strategy training school policy) on the characteristics of a psychosocial support, characterized by continuity, since their processes and dynamics of daily life under the premise of generating practice usually gather, organize, without ignoring the presence of the conflicts that underlie these collective processes, but by overlaying the definition of collective interests, with all the contradictions and constraints that it implies.

Key words: Forced displacement, injury, psychosocial support. 


\section{EL LUGAR DE LA ACADEMIA COMO ESCENARIO DE REFLEXIÓN DEL CONTEXTO SOCIAL}

Decía Jaime Garzón que la Universidad nació como el espacio por excelencia de las ideas, donde era posible encontrar la universalidad del conocimiento, es decir, la cantidad acumulada del conocimiento elaborado históricamente por los hombres y que, compilado y archivado, podía estar al servicio de otras generaciones, permitiéndole a los seres humanos en particular y a las sociedades en general, preguntarse, pensarse y comprenderse a si mismos, en una polifonía de voces y posturas sobre el mundo, que a su vez le concedieran su propia recreación.

Desde este lugar, la Universidad cumple con tres funciones fundamentales a saber, en relación con la sociedad y la vida individual y colectiva de los seres humanos: la reproducción del conocimiento acumulado, la Docencia; la generación de nuevo conocimiento, la investigación; y la incidencia en la vida social con esos conocimientos, la extensión. Cada uno de ellos como un complemento y una necesidad de los otros, donde se reafirman, se confrontan y se reconstruyen en su urgente necesidad de interpretar el mundo, utilizando el vehículo de la ciencia como instrumento principal de su acción:

"[...] la ciencia es una forma de relación social ligada a la vida, una forma de conocimiento ligada histórica y culturalmente, un conjunto de prácticas que se perfilan desde perspectivas de búsquedas determinadas; es también el remanente de saber que queda de todas las prácticas y todas las búsquedas. La ciencia no solo esta en las respuestas y en las soluciones, sino en las preguntas, en las formulaciones de problemas, en los hallazgos y en todo lo que va quedando en el camino en torno a los ejercicios investigativos, en las hipótesis desechadas, en las pesquisas, en los borradores, en los errores" (Botero, 1998:541)

En este orden de ideas, el grupo de investigación Sujetos y Acciones Colectivas de la Escuela de Trabajo Social y Desarrollo Humano de la Universidad del Valle se conforma hacia inicios del 2004, pretendiendo aportar a la construcción de conocimiento socialmente relevante en los temas que nos implican: la constitución de sujetos sociales y políticos y 
las acciones colectivas. Estas últimas a través de la historia han jugado un papel fundamental en los procesos de cambio social y re-configuración de las sociedades, así como en la constitución de sujetos sociales y políticos. Temas que hoy cobran gran importancia en el contexto mundial, en las realidades latinoamericanas y en el caso colombiano en particular. Esta construcción de conocimientos y acciones las entendemos en conexión y desarrollo de cara a y con actores sociales particulares, en escenarios específicos, que lleven de alguna manera a procesos de transformación social y de mejoramiento de las condiciones de vida de la población; y no como una ciencia a espaldas de la realidad, una investigación desde la prepotencia del conocimiento ilustrado o una acción salvadora externa, casi mesiánica, de quien "sabe que hacer".

De allí la urgencia de la reflexión constante que el grupo desarrolla desde hace cuatro años por medio del seminario permanente sujetos sociales y acciones colectivas, que en sus tres versiones ${ }^{1}$ cuenta hoy día con la producción de dos textos que recogen dicha discusión ${ }^{2}$. Además, el imperativo ético de "hablar con conocimiento de causa", nos ha llevado a cercarnos de distintas formas al fenómeno del desplazamiento forzado, primero desde el ejercicio de la investigación, a partir del proyecto "acciones colectivas y constitución de sujetos sociales y políticos. Estudio sobre organizaciones de personas en situación de desplazamiento forzado en sectores populares de la ciudad de Cali"’3; luego desde el acompañamiento

${ }^{1}$ En el 2004 el seminario permanente nace bajo el nombre que hoy lo caracteriza, "Sujetos sociales, acciones colectivas y trabajo social", con la pretensión de discutir teóricamente esos temas con la participación del Estudiantes, profesores y egresados de la Escuela de Trabajo social y desarrollo humano de la Universidad del Valle. Hacia el 2005 el seminario permanente se concentra en el estudio del fenómeno del desplazamiento forzado por la violencia, articulando sus temas centrales de discusión (sujetos sociales y políticos y la acción colectiva), con el ánimo de "aterrizar" las discusiones teóricas a referentes empíricos concretos y cotidianos del contexto local, regional y nacional. Ya durante 2006 y tras una convocatoria interna de investigación en la universidad del Valle, el grupo discute y reflexiona en torno a las organizaciones de personas en situación de desplazamiento forzado, como objeto de estudio de un proyecto investigativo en el que se inscribe y que se desarrolla durante el año 20062007.

${ }^{2} \mathrm{Al}$ respecto revisar:

Sujetos sociales, acciones colectivas y trabajo social (2005). Escuela de trabajo social y desarrollo humano, Facultad de Humanidades - Universidad del Valle. Cali

Revista prospectiva $\mathrm{N}^{\circ} 10$ (octubre 2005). Tema central: Desplazamiento forzado Escuela de trabajo social y desarrollo humano, Facultad de Humanidades - Universidad del Valle. Cali.

${ }^{3}$ Esta investigación fue financiada en la convocatoria interna 2006 de la vicerrectoría de investigaciones de la Universidad del Valle. 
a algunas organizaciones de población desplazada en Cali, desde sus dinámicas internas y la reivindicación de derechos, ante la gravedad de su situación de desprotección y la multidimensionalidad de la vulneración de sus derechos.

Con todo ello, asumimos la exigente tarea de indagar, discutir y disertar colectivamente sobre las organizaciones de personas en situación de desplazamiento (P.S.D.) en la ciudad de Cali, bajo el imperativo ético de la "convicción responsable" (Estrada, 2004), es decir, bajo el constante cuestionamiento "por el sentido de la investigación y la intervención social, que involucra directamente la acción social, el contexto y los efectos que de se derivan de ella" (Rodríguez y otros, 2005:160). De allí que presentemos a continuación y en este escenario, algunas reflexiones respecto al ejercicio de acompañamiento a organizaciones de personas en situación de desplazamiento, que desarrollamos desde la estrategia Escuela de formación política ${ }^{4}$, para lo cual haremos referencia a: 1) la comprensión que tenemos del fenómeno como una problemática socialmente relevante, de carácter político y con efectos traumáticos para la vida individual y colectiva; 2) tratando de dimensionar su magnitud en el contexto regional y local, particularmente desde una lectura de orden psicosocial; y así, 3) poder interpretar las acciones adelantadas en dicho acompañamiento, rescatando los aprendizajes logrados en este proceso de acción -reflexión.

\section{EL DESPLAZAMIENTO FORZADO EN COLOMBIA COMO PROBLEMÁTICA SOCIAL Y POLÍTICA}

Asumimos el desplazamiento forzado desde la concepción que propone Martha Nubia Bello, como:

${ }^{4}$ La propuesta Escuela de formación política para miembros de organizaciones de personas en situación de desplazamiento surge como una estrategia de acompañamiento demandada por algunos líderes de organizaciones de personas en situación de desplazamiento que participaron activamente en el desarrollo de la investigación sobre organizaciones de PSD en Cali, adelantada por el grupo de investigación Sujetos y Acciones Colectivas de la Universidad del Valle, en el ánimo de establecer una respuesta ética al ejercico investigativo, atravesado por el cuestionamiento de ¿investigar para qué? . La Escuela de Formación Política, como común mente se le llamó, fue implementada en el periodo febrero - septiembre de 2007, en el marco del proyecto Implantación de Herramientas para la Paz y la Convivencia, cogestionado desde la Consejería municipal de Paz (DESEPAZ) y la Corporación Juan Bosco, con financiamiento de la OIM, FUPAD y USAID. 
"la manifestación más clara de la permanencia histórica y la consolidación de un modelo de desarrollo excluyente caracterizado, además por relaciones clientelistas, corruptas, de patronaje y de fuerza. Estas relaciones configuran el telón de fondo del conflicto armado interno" (Bello, 2004:20).

constituyéndose en una estrategia que permite la consolidación del modelo que se quiere imponer, por tanto entre más ruptura haya del tejido solidario y social, entre más expulsión de comunidades ocurran, entre más se aniquilen los procesos organizativos y participativos de las comunidades, será más fácil la imposición $\mathrm{y}$, por su puesto, la no participación de la población en los procesos de construcción de desarrollo de un país, de un Estado y de una nación; así serán unos pocos los que a nombre de muchos consoliden sus intereses.

Desde esta perspectiva, el desplazamiento forzado se constituye en "una situación límite reflejada en una experiencia traumática de carácter político" (op.cit), en cuanto denota los problemas estructurales de marginación, exclusión y negación histórica de buena parte de la población respecto a los ordenes económico, social, político y cultural que constituye la vida cotidiana de los pobladores del territorio colombiano; mientras simultáneamente afecta de manera contundente "la dimensión personal, familiar y comunitaria de las personas que se encuentran en tal situación [de desplazamiento]" (ídem 2005), en la medida que funda, en palabras de María cristina Palacios (2004), "órdenes de facto" soportados en el terror, el miedo, la desconfianza y el aislamiento, entre otros, para imponer lógicas relacionales, económicas y políticas convenientes solo a sectores muy reducidos de la sociedad.

"[...] el desplazamiento forzado es un proceso complejo que enlaza en el enfrentamiento bélico entre distintos actores, el requerimiento del control territorial, configurándoseuna lógicadelaguerraquecombinalamulticausalidad, la multipolaridad y la multidimensionalidad5. El desplazamiento forzado, al

5 "La multicausalidad hace alusión a las diversas causa que impulsan el enfrentamiento armado entre los diferentes actores para definir el control sobre el territorio y garantizar: el control social, el control del suelo, el control de la vías para el transporte y comercialización de productos ilícitos y el control de los beneficios que reportan los recursos naturales. La multipolaridad tienen que ver con el orden de turbulencias desatados por los enfrentamientos y alianzas entre los diferentes actores del conflicto, $[\ldots]$ que involucran a la población civil como estrategia de guerra o como objetivo militar. 
igual que el conflicto armado, son otras formas de nombrar la violencia que recorre todos los ámbitos de la vida social" (idem: 36)

Pero esta no es una situación nueva en la historia colombiana. Éste fenómeno es un eje de pervivencia histórica, una realidad recurrente y casi permanente de la historia nacional. Desde la conquista misma, miles de indígenas se vieron sometidos a un movimiento constante y forzoso por el territorio nacional para evitar desaparece como cultura.

"En el siglo XIX, la guerra de independencia y las guerras civiles que enfrentan al débil Estado central con proyectos regionales, impulsan nuevas olas de migrantes que intentan alejarse de las amenazas y la dominación de sus antagonistas. Una de estas olas migratorias significativas se registra en 1898, bajo el marco de la guerra de los mil días

Las migraciones forzadas se multiplican durante la violencia bipartidista de mediados del siglo XX, cuando, según algunos investigadores, se desplazaron cerca de 400.000 familias campesinas, fueron asesinadas aproximadamente 180.000 personas y quedaron abandonadas cerca de 400.000 parcelas. Se estima que 2 millones de personas huyen de las persecuciones y de la violencia generada por los grupos armados legales e ilegales, que actúan a nombre de los partidos tradicionales. Esta migración propicia una modificación de la estructura agraria, basada en la expropiación y la compra de pequeñas y medianas propiedades por parte de terratenientes y empresarios agroindustriales." (REDIF, 2007a:1)

Las dos últimas décadas del siglo XX, con el fortalecimiento y ampliación del pie de fuerza de las organizaciones insurgentes, los fallidos procesos de paz entre estos y el Estado, por un lado; el auge del narcotráfico y el incremento de sus ejércitos privados, por otro; la aparición oficial y el proceso expansivo de las Autodefensas Unidas de Colombia (y en general los grupos paramilitares que se vinculan a esta "franquicia de la guerra"),

\footnotetext{
Y, finalmente, la multidimensionalidad se refiere a los diversos espectros que incorpora y atraviesa. Condiciones que tienen que ver con análisis macro, meso y micro estructurales, en los cuales se entretejen aspectos económicos, políticos, sociales, culturales, ambientales, que ponen en evidencia la situación del Estado, de la organización social y de las subjetividades; y producen una dinámica de desestructuración y reestructuración del orden social". (Palacio, 2004:36).
} 
con mayor fuerza en la segunda mitad de los años noventas y los primeros años del nuevo siglo; y el recrudecimiento de las estrategia bélica del Estado para "recuperar la soberanía y el control" sobre el territorio nacional que históricamente desatendió; el desplazamiento forzado se convierte en una situación que desbordar los límites de la capacidad operativa del Estado y la tolerancia ética de la sociedad para invisibilizar el profundo drama humanitario, social, político y económico que se desprende de ello.

La confrontación por el control del territorio, la apropiación de facto de bastas extensiones de tierras agroproductivas o que contienen algún tipo de recurso natural de alta rentabilidad -incluidos los biorecursos o recursos genéticos-, demuestran que no solo las lógicas del desplazamiento forzado corresponden a los efectos de la guerra (condiciones político-ideológicas) y la ocupación de territorios estratégicos para la acción militar de los distintos grupos en pugna, sino que además esconde y se asocia a dinámicas de orden profundamente económico, donde aparecen narcotraficantes, ganaderos, capitalistas nacionales y transnacionales. De allí la frase de Héctor Mondragón (1998) "no hay desplazados porque hay guerra, sino que hay guerra para que haya desplazados":

"[...] El desplazamiento no sólo puede interpretarse como una consecuencia de la confrontación, también es una estrategia de guerra que permite la apropiación de territorios para el establecimiento de grandes proyectos de inversión, el desarrollo de economías ilícitas y el lavado de activos, entre otros" (op.cit)

La situación para el Valle del Cauca, como en buena parte del resto del país, logra niveles dramáticos, que además de ubicar el desplazamiento forzado como una problemática social y política, también la establece como una compleja catástrofe humanitaria. En la totalidad de los municipios se han presentado eventos de expulsión de la población y en los años comprendidos entre 1998 y 2006 el $100 \%$ de los municipios han tenido que responderá a su situación como receptores de $\mathrm{PSD}^{6}$.

\footnotetext{
${ }^{6}$ Los datos aquí consignados son tomados de documentos oficiales de la oficina de gestión de paz de la gobernación del Valle del Cauca, en el documento: Plan Integral Único Departamental (PIUD2007)
} 
Según las cifras oficiales del SIPOD $^{7}$ de Acción Social, en el departamento se registraron 82.782 PSD a diciembre de 2006, mientras los datos de la gobernación muestran un acumulado de 100.146 PSD hasta el 31 de diciembre de 2007; mientras tanto, en lo referido al departamento como lugar de recepción, el mismo SIPOD registra 116.392 casos. Esto lo ubica como el noveno departamento expulsor de la población a nivel nacional, donde es particularmente dramática la situación del distrito de Buenaventura con 54.446 casos individuales registrados, correspondientes a 9.762 familias, ha febrero de 2008, que contribuyen con el $37 \%$ y $31 \%$ del total departamental respectivamente ${ }^{8}$. De cualquier forma y aunque las cifra son extremadamente altas, habría que tomar distancia dado el subregistro permanente en este fenómeno o la asociación a fenómenos paralelos como el confinamiento.

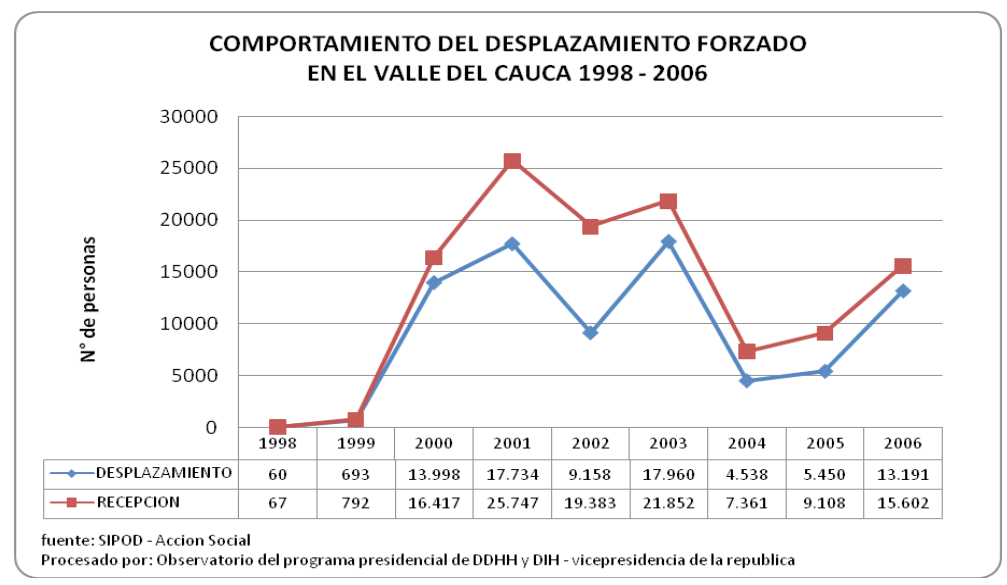

No solo la magnitud de personas afectadas sino, además, la profundidad de los niveles de la afectación y la múltiple y reiterada violación de sus derechos humanos y las permanentes infracciones al Derecho Internacional Humanitario completan el panorama de catástrofe humanitaria que se configura en torno al desplazamiento forzado. Los desplazados son obligados

${ }^{7}$ SIPOD: sistema de información de población desplazada.

${ }^{8}$ Los datos son tomados del conversatorio ofrecido por el Defensor Comunitario de la costa Pacifica - Defensoría del Pueblo, T.S. Eduardo Areiza, "derechos humanos y victimización en el distrito especial de Buenaventura", en la Universidad del Valle - sede pacifico (mayo 2008). 
a huir de su territorio, a dejar todo abandonado, incluso sus costumbres y sus redes de apoyo familiares, comunitarias, negándoles el derecho a la autodeterminación de su existencia, al libre transito por el territorio, a la asociación, so pena de ser asesinados; además, los desplazamientos se presentan en el marco de asesinatos, masacres, torturas y violaciones, comprometiendo directamente sus derechos fundamentales a la vida, la integridad física, la salud, sus derechos sexuales y reproductivos, etc. Llegan a las grandes ciudades a engrosar -la mayoría de las veces- los cordones pobreza y miseria de las zonas periféricas de la urbe, donde las condiciones de vida son -de por si- denigrantes de la condición humana, no gozan de servicios públicos o la calidad de estos es deficiente, su vinculación a los servicios de salud constituye toda una travesía, que cuando logra resolverla no cubre ni los traumas ni tratamientos de alto costo para enfermedades que pudieron haber sido agravadas por el desplazamiento; llegan a estos lugares porque las opciones son reducidas y hay que "mantener la vida". En los sitios de llegada son discriminados por su condición, como si fuesen ellos los causantes de su situación, son revictimizados en tanto se les asocia como actores del conflicto, por lo que se les vuelve a excluir, se les margina, se les niegan las oportunidades, que además son pocas.

Tal es la dimensión del problema que la misma Corte Constitucional se pronunció en el 2004 con una sentencia de tutela que se constituyó en hito jurisprudencial al declarar el Estado de Cosas Inconstitucionales para el desplazamiento forzado (sT025/04), es decir que "la reiterada, prolongada y masiva violación de sus derechos obedece a un problema estructural relacionado con la política de atención y que no existe concordancia entre la gravedad de la afectación de los derechos reconocidos a esta población y la cantidad del recurso efectivamente destinados a asegurar el Goce Efectivo de tales Derechos (GED) y la capacidad institucional para implementar los correspondientes mandatos constitucionales y legales"

El fenómeno del desplazamiento forzado por la violencia y la consecuente aparición de la PD, ha puesto en entre dicho la capacidad y legitimidad del Estado en cuanto sus principios fundamentales y constitutivos (social y de derecho), pues muestra la incapacidad para hacer de estos preceptos una realidad fehaciente y empírica. 


\section{DESPLAZAMIENTO FORZADO Y LOS DAÑOS PSICOSOCIALES}

La población en situación de desplazamiento, obligada a abandonar su tierra para proteger su integridad física, se convierte en víctima que sufre una serie de daños, pérdidas y transformaciones abruptas que afectan dramáticamente su estabilidad, seguridad y capacidad para decidir e incidir sobre su vida y vislumbrar un futuro deseable. Esta serie de daños y pérdidas se dan tanto a nivel individual como familiar y comunitario, en tanto a partir del desplazamiento se desestructuran las redes y los vínculos sociales, los aprendizajes, los sentidos y los significados que constituyen las identidades individuales y colectivas ${ }^{9}$.

En este sentido el desplazamiento constituye una "afectación del SER. Al vulnerarse negativamente aspectos esenciales de la vida humana como la identidad, la autonomía, la estabilidad, la seguridad vital (vivienda, trabajo, alimentación) y la seguridad existencial, se provocan vivencias y sentimientos profundos de indefensión, miedo, angustia, sinsentido, rabia e impotencia." (Redif, 2007b). Es así como a través del desplazamiento forzado, se deterioran los soportes sociales y espirituales y, en consecuencia, se coloca a las personas y a sus comunidades en condiciones de extrema desprotección y vulnerabilidad.

Siguiendo al profesor Max-Neef (2003) podríamos inferir que los efectos psicosociales del desplazamiento forzado alteran dramática y

\footnotetext{
${ }^{9}$ Se asume el concepto de identidad como la construcción que se hace de si mismo a partir de la relación con los otros, es un proceso en el cual confluyen la historia individual, las vivencias y el contexto en que se encuentran las personas. En tal sentido es dinámica, cambiante y da lugar a ser reconstituida permanentemente. En particular "la Identidad Colectiva permite identificar al actor en su dimensión social. Por lo tanto esta no podría trata de características absolutas y homogenizantes, aplicables a todos los que participan del los procesos sociales (refiriéndonos a la Acción Colectiva) en términos de su constitución individual, como sustrato único e indiferenciado que porta cada individuo por el hecho de serlo o por el hecho de participar en ellos, como podrían entenderse desde las corrientes esencialistas del desarrollo, para el caso, paradigmas como el psicoanálisis, el estructural funcionalismo o distintas corrientes del marxismo. Por el contrario, convoca a considerar la red de múltiples relaciones e interacciones que el actor social establece con los otros similares a él durante el proceso, en la espaciotemporalidad en que este tiene lugar y a partir de las cuales va constituyendo, por identificación y/o diferenciación, su modo de ser y estar en el mundo y de afrontar colectivamente la acción" (Erazo y Delgado, 2005).
} 
patológicamente al menos dos dimensiones centrales en las necesidades humanas ${ }^{10}$ : la seguridad vital y la seguridad existencial.

La seguridad vital, entendida en clave de derecho, hace referencia a las condiciones materiales necesarias para que las personas garanticen la subsistencia fisiológica de su ser, por cuanto una afectación sobre esta dimensión compromete fundamentalmente la vida (incluida la salud y la integridad física) y la existencia de afectado y su dignidad. El desplazamiento forzado, como lo hemos explicitado frecuentemente, desestructura estas condiciones materiales de la existencia (individual y colectiva) a partir del destierro, la expropiación, el desalojo, entre otras.

Por su parte, la seguridad existencial, también en la perspectiva de derechos, estaría asociada la garantías para la definición de la condición humana propiamente dicha, no solo fisiológica, sino relacional, que implica la integración del sujeto a las redes de relaciones que constituyen su mundo humano, es decir, la identidad, los universos simbólicos, las redes de apoyo social, las condiciones subjetivas, las normas y valores, etc., sobre los cuales tiene sentido la existencia humana. El impacto del desplazamiento forzado es profundamente devastador en esta dimensión, en tanto la coacción por la vía de las acciones de fuerza, que soportan los órdenes de facto con toda la carga simbólica del poder y la dominación, limita, restringe o anula las formas organizativas, las estructuras políticas, las prácticas sociales, las representaciones de la autoridad y el poder, la tergiversación de los valores y los comportamientos históricamente correctos para vivir en comúnunidad.

En tal caso, desde una perspectiva psicosocial, estas dimensiones se complementan mutuamente, y en el evento y situación de desplazamiento ambas son afectadas simultáneamente, no se distinguen, por el contrario se dan sucesivas yuxtaposiciones entre ellas y se viven como una sola cosa, que es incomprensible y sinsentido.

${ }^{10}$ Para el Profesor Manfred Max-Neef (2003:37) "las necesidades revelan de la manera mas apremiante el ser de las personas, ya que aquel se hace palpable a través de estas en su doble condición existencial: como carencia y como potencialidad. Comprendidas en un amplio sentido, y no limitadas a la mera subsistencia, las necesidades patentizan la tensión constante entre carencia y potencialidad tan propia de los seres humanos. [...] concebir las necesidades tan solo como carencia implica restringir su espectro a lo puramente fisiológico, que es precisamente el ámbito en que una necesidad asume con mayor fuerza y claridad la sensación de <falta algo > ". 


\section{QUE ES COMO SE ASUME EL ACOMPAÑAMIENTO PSICOSOCIAL}

Las múltiples investigaciones realizadas alrededor de las consecuencias en la salud mental que genera el desplazamiento forzado y la investigación sobre dinámicas organizativas de población en situación de desplazamiento en la ciudad de Cali realizada por nuestro equipo de investigación, nos permitió tener presente que, a la hora de realizar un acompañamiento a víctimas de violencia política, debíamos reconocer múltiples dimensiones de la vida de los sujetos con los cuales se desarrollaría un proceso de acompañamiento, esto es, por un lado reconocer su condición de persona que ha padecido rupturas que pueden alterar sus relaciones familiares, comunitarias, las representaciones frente a sí mismo y frente al mundo, y por otro lado, concebir un sujeto con capacidades para incidir sobre el curso de su vida. Se es víctima en cuanto sus derechos han sido transgredidos por actos de fuerza y violencia y a la vez se es sujetos en tanto se le reconoce la capacidad de la para superar su condición

Para nosotros, un proceso de de atención psicosocial con víctimas del desplazamiento forzado debe apuntar, como lo plantea Martha Nubia Bello (op.cit, 2005), a fundamentar procesos de acompañamiento personal, familiar y comunitario, que busquen restablecer la integridad en las víctimas, disminuir el sufrimiento emocional, fortalecer la identidad, reconstruir el tejido social, así como reparar los derechos vulnerados". Tener presente estas múltiples dimensiones, condiciones y ámbitos en los cuales el sujeto se desenvuelve, consideramos, debe apuntar a un enfoque de atención psicosocial integral, en tanto como bien lo expresara Sócrates hace 400 años antes de nuestra era: "Así como no puede curarse los ojos sin atender la cabeza, ni puede curarse la cabeza sin atender el cuerpo, así tampoco puede curarse el cuerpo sin atender el alma" y para atender el alma de una sociedad que ha padecido los horrores del desplazamiento forzado interno, los sujetos implicados deben reconocer el proceso histórico-político de violación de sus derechos e implicarse en la búsqueda por la restitución de los mismos.

En este sentido reconociendo nuestras capacidades y limitaciones como grupo académico que ha orientado su trabajo a la comprensión de las acciones 
colectivas y aceptando la invitación de las víctimas del desplazamiento, nos dimos a la tarea de pensar y materializar un acompañamiento que trascendiera el enfoque patologizante ${ }^{11}$, a través del cual se brinda apoyo emocional para que el sujeto aprenda a sobre vivir e integrarse al contex to de llegada. Fue así como construimos una propuesta que apuntara a un proceso de acompañamiento que le permitiera a las personas, a través de un espacio que denominamos "Escuela de Formación Politica", la reconstrucción de vínculos individuales y colectivos, trabajando con hombres y mujeres líderes de organizaciones de población en situación de desplazamiento el reconocimiento del contexto sociopolítico, de los derechos vulnerados y los derechos a la reparación; promoviendo solidaridades y la esperanza sobre un futuro deseado ${ }^{12}$, que apuntara a restablecer el sentido de seguridad existencial, necesario en las víctimas; así mismo, nos planteábamos que el proceso formativo debía permitirle a los participantes la cualificación de la acción de las organizaciones a las cuales pertenecen, a propósito del extenso marco normativo que, en aras de garantizar jurídicamente los derechos de la población desplazada, termina por obstaculizar el resarcimiento de sus derechos.

El esfuerzo por construir un espacio de formación política con los líderes de las organizaciones de PSD de la ciudad de Cali, fue un intento por dar respuesta a los retos que este periodo histórico le propone a una sociedad que, como la planteara Pablo Freire (1986), "se convierte en una sociedad sin pueblo; donde el hombre sencillo y sin conciencia está cada vez más relacionado a una cosa, en tanto otros pueden decidir por él”, discurso que puede sonar metafórico pero que directamente podemos relacionar con nuestra sociedad, al mirar las cifras de mas tres millones de personas en situación de desplazamiento que dejan sus tierras bajo la voluntad de otros.

${ }^{11}$ Aquel en el que la víctima se engloba en una condición de indefensión, de carencia total, desconociendo su historia, sus recursos personales para el afrontamiento de la situación, incluso desconociendo su perspectiva de mundo, aquella construida antes del desplazamiento y que es suplantada, en la patologización, por la perspectiva de mundo del agente externo, de quien interviene en la problemática.

${ }^{12}$ Desde la perspectiva freiriana de la pedagogía liberadora, un principio constitutivo y pedagógico en toda acción de formación es el realismo crítico esperanzador, es decir, una conciencia crítica del mundo inequitativo, desigual, marginalizante en que se vive, que constituyen el límite material de la existencia, pero a la vez el reconocimiento de alternativas en ese escenario desfavorecedor a partir de la transgresión de esos límites. Al respecto revisar Freire, Paulo (1980), pedagogía del oprimido. Siglo XXI editores. Capítulos 2 y 3. 
Caminar hacia la búsqueda de una sociedad donde el hombre pueda ser realmente hombre dejando de ser cosa y pueda ser sujeto que conozca de donde viene y cuál es su historia, para que pueda clarificar hacia donde ir, es una de las pretensiones que guían nuestra concepción de los procesos formativos.

En todo proceso formativo están en juego ideas de país, formas particulares de entender el mundo y la sociedad. Cada proceso formativo tiene una intencionalidad, unos fines, y para nosotros un espacio de formación con población víctima del desplazamiento forzado debía ir más allá de entregar unos contenidos de tipo técnico ${ }^{13}$, solamente de conocer decretos, normas, (sin negar su importancia). Nuestra pretensión estuvo orientada a deconstruir y reconstruir marcos de referencia, visiones del mundo, para potencializar sujetos que conozcan su realidad y actúen para transformarla, ello implicó un intento de construir espacios de encuentro y desencuentro de líderes de diversas organizaciones del la ciudad de Cali, que permitiera realizar construcciones conjuntas, potenciando ciudadanos críticos frente a las lecturas de la situación que les ha tocado padecer en carne propia, posibilitando revisar las lógicas organizativas, los intereses comunes trazados por ellos, orientados a la exigibilidad de los derechos vulnerados a raíz del destierro.

Nuestro acompañamiento estuvo enfocado en procesos más que en resultados, nos interesaba que a través de la pregunta y de las reflexiones colectivas sobre las situaciones, los participantes pudieran constituir nuevos sentidos de su realidad y nuevas respuestas a las situaciones que se enfrentan actualmente.

A través de la formación se pretendía generar inquietudes, desquebrajar esas certezas que conllevan a creer que "nos las sabemos todas". El ejercicio formativo debía permitirles preguntarse quienes eran y hoy quienes son, que se ha perdido y que ha ganado a raíz del desplazamiento, debía permitirles reconocer, a través de sus narrativas, las múltiples pérdidas generas por el desplazamiento y las diversas formas de asumir dichas pérdidas,

\footnotetext{
${ }^{13}$ Lo técnico como una mera forma estandarizada de actuar en función de la efectividad de los resultados. y no tanto preguntándose por la pertinencia de cada situación particular. Lo técnico se resuelve en las mejores formas de hacer. el pensar se resuelve en las formas apropiadas -para un contexto o situación determinada- de comprender la situación..
} 
reconocer los derechos vulnerados y de acuerdo a ello, ubicar la relevancia de constituir acciones que propendan por una sociedad distinta o por lo menos un accionar de las organizaciones de desplazados que trascienda las demandas puntuales, la inmediatez, el silencio y la desintegración reinante en las organizaciones.

\section{APRENDIZAJES DESDE LA EXPERINCIA}

Uno de los retos que nos propusimos con profesores y profesionales quienes participamos en la orientación de la escuela al iniciar el proceso, fue bajar los discursos y lenguajes académicos de un modo que fueran procesados, legibles y pertinentes para personas que en su gran mayoría provienen del pacifico colombiano y la región andina, personas con un nivel escolar mínimo pero con una riqueza cultural y oral incalculable. Teniendo en cuenta estas particularidades en el encuentro continuo con estos hombres y mujeres, fuimos aprendiendo sus formas de aprendizaje, por ello, los talleres partieron de las vivencias cotidianas, contando y escuchando sus historias, reconociendo las propias en la de los otros, lo cual acercó la resignificación de las experiencias pasadas y presentes, estos encuentros a partir de la risa, el juego y la discusión, proveen cambios en la forma en que las personas reconstruyen sus experiencias pasadas, en La medida que la historia individual se escucha en relación con la de los otros, permitiendo realizar una conexión entre los eventos pasados y el presente. Al evaluar participativamente la experiencia, nos encontramos que las jornadas de de escuela en las cuales se desarrollo un trabajo de tipo magistral no fueron significativas, ni lograron generar los aprendizajes que esperábamos en ellos.

Por otro lado, este ejercicio permitió reconocer que en el mundo de las organizaciones, existen distintos niveles e intereses, que existen liderazgos autoritarios, organizaciones donde prima la búsqueda del logro individual sobre el interés colectivo, esto no es otra cosa que la primacía de los valores que la sociedad moderna le plantea al individuo, sin embargo desde la academia en ocasiones intentamos comprender una sociedad en blanco y negro, vemos "con los ojos de la teoría" o del ideal, lo cual impide reconocer 
los condicionantes y contradicciones propias de la condición humana, a los que la gente se enfrenta en su día a día. Dentro de los talleres realizados con ellos, trabajamos sesiones enteras sobre sus limitaciones como organizaciones, la poca claridad en sus intereses comunes, la deficiencia de sus estrategias y medios para hacer visibles sus demandas, sus historias previas al evento del desplazamiento, pero poco trabajamos los logros de sus luchas hoy como organizaciones en Cali, las historias de sus tomas, marchas y espacios de concertación. Reconstruyendo las narrativas que han elaborado alrededor del estar juntos, pues a veces olvidamos que el solo hecho de permanecer juntos se puede constituir en un acto de resistencia cuando se han experimentado perdidas y rupturas en los vínculos sociales como las que trae el desplazamiento forzado.

Sin embargo, también es importante matizar esta situación; frente a un acompañamiento a la PSD, bien desde sus dinámicas organizativas o desde la atención individual y familiar, hay que partir de que son personas desgajadas de su territorio, de su cultura y de su vida, que los vulnera y los ubica en una situación de plena fragmentación social, tanto con sus referentes históricos como en sus contextos de llegada -que son siempre extraños-, de allí que los agravios no sean suficientes para generar acción colectiva, y menos si esta se ubica en el terreno de lo público, cuando lo que buscan es su invisibilización a causa del miedo y el terror que los persigue. Tomemos distancia de Marx cuando dio por sentado que basta con tener una condición (como la de obrero, pobre o desplazado) para hacer conciencia de esta, ya la historia nos lo ha mostrado y en Colombia nos lo sigue demostrando, el tejido y los intereses comunes son construcciones sociales. Creemos que uno de los mayores potenciales de la escuela de formación política ha sido propiciar un espacio para esa construcción social, en el que hubo acompañamiento de los profesionales externos que operan como facilitadores e interlocutores de unas realidades cotidianas de la población. Un reto frente a la ruptura es la reconstrucción del tejido.

Discutir las causas, consecuencias y alternativas a la problemática del desplazamiento, con los actores que las sufren y padecen, desde los procesos de reflexión colectiva, donde cada uno aporta a la construcción y comprensión conjunta de una realidad compleja, consideramos es una 
tarea necesaria en el camino por superar los asistencialismos que perpetúan las condiciones de pauperización, marginación y exclusión de la población en situación de desplazamiento, que atentan contra el principio de dignidad consagrado constitucionalmente en nuestro país; de esta manera avanzar en el reconocimiento de su condición y visualización en el escenario público como actores determinantes en procesos de construcción de sociedad, como ciudadanos y ciudadanas de esta tierra que también es suya. Siguiendo a Pilar Riaño (2006):

"los procesos de reconstrucción de los proyectos de vida y las luchas por el restablecimiento de sus derechos como sujetos sociales de la población desplazada, están ligados a la labor de resignificación del pasado"

Compartimos esta concepción, en tanto es difícil construir un horizonte nuevo de posibilidades cuando no se reconocen los procesos que han llevado a que históricamente se produzcan desplazamientos involuntarios de la población. Hablar de recuperación de la memoria desde una dimensión política implica reconstruir los procesos vividos por la población como mecanismo para impedir el olvido y el silencio que ha caracterizado la historia del país, así como trabajar con la población en el reconocimiento de las raíces estructurales que han producido la recomposición forzada del territorio a través de la historia de Colombia.

Por otro lado, reconocemos que un ejercicio de acompañamiento que propenda por que las personas reconozcan su condición para actuar sobre la exigibilidad de sus derechos, debe trascender la formación a través de talleres en un periodo determinado, el acompañamiento debe ser continuo, siguiendo sus procesos cotidianos, la práctica habitual de juntarse, organizarse, los conflictos en estos procesos colectivos y, sobre todo, la definición de intereses colectivos, con todas las contradicciones y obstáculos que ello implica; sin embargo la falta de recursos humanos y financieros limitaron y limitan la posibilidad que, como grupo de investigación, tenemos para entablar un proceso continuo con las organizaciones de personas en situación de desplazamiento de la ciudad. 


\section{BIBLIOGRAFÍA}

BELLO, Martha Nubia (2004). Efectos psicosociales y culturales del desplazamiento forzado. Universidad Nacional de Colombia. Bogotá.

BELLO, Martha Nubia y LANCHEROS Dora Lucía (2005). Acompañamiento Psicosocial y atención humanitaria en el contexto colombiano. Corporación AVRE - COSUDE. Bogotá.

BOTERO Uribe, Darío (1998). Universidad y saber. En el poder de la filosofía y la filosofía del poder. Tomo II. Universidad Nacional de Colombia. Bogotá.

Censo General 2005: Nivel nacional. Departamento Administrativo Nacional de

Estadistica (DANE). Bogotá. Consultado en: http://www.dane.gov.co/censo/ files/libroCenso2005nacional.pdf

ERAZO, David y DELGADO, Alexandra (2005). Identidad Colectiva: Proceso y producto social. En Sujetos sociales, acciones colectivas y trabajo social, Seminario Permanente Sujetos y acciones colectivas -Escuela de Trabajo Social y Desarrollo Humano, Cali, Universidad del Valle.

ERAZO, David y TORRES V., Liliana (2005). Hacia nuevas lecturas y acciones frente al desplazamiento en Colombia: una mirada desde la perspectiva de los sujetos sociales. En revista prospectiva $N^{o} 10$. Tema central: desplazamiento forzado. Escuela de Trabajo social y desarrollo humano, facultada de humanidades - Universidad del Valle. Cali.

ERAZO, David (2008). Marco general de los derechos de la PSDF en Colombia. Grupo de Investigación Sujetos y Acciones Colectivas (Documento de trabajo - interno). Inédito.

ESTRADA, Víctor Mario (2004). Implicaciones ético - políticas y ético - metodológico - técnicas de la formación académica en una sociedad globalizada. En revista colombiana de trabajo social $N^{o} 19$. CONETS. Cali

Freire, Paulo (1980), pedagogía del oprimido. Siglo XXI editores. Buenos Aires - Argentina.

FREIRE, Pablo (1986). Educación como práctica de la libertad. Siglo XXI editores $-4^{\circ}$ edición. Bogotá Colombia

Gobernación del Valle del Cauca (2007). Atlas de paz y convivencia. Oficina de gestión de paz y convivencia. FUPAD - USAID - OIM. Cali. Consultado en: http://www.valledelcauca.gov.co/gestionpaz/publicaciones.php?id $=3560$

MAX-NEEF, Manfred y otros (2003). Desarrollo a escala Humana. Una opción para el futuro. CEPAUR - Fundación Dag Hammarskjöld. Medellín, Colmbia MONDRAGÓN, Hector (1998). Relatifundización, megaproyectos y campesinos en Colombia. Consultado en: www.gratisweb.com/ciclocrisis/latifundio.htm 
PALACIOS, María Cristina (2004). Familia y violencia familiar. De la invisibilización al compromiso político. Departamento de estudios de familia. Universidad de Caldas, Manizales.

REDIF (2007a). la perspectiva histórica del desplazamiento forzado en Colombia - modulo 2 unidad 2. En Cátedra virtual Desplazamiento forzado en Colombia. Universidad Nacional de Colombia - ACNUR - PIUC. Bogotá.

REDIF (2007b). Impactos sicosociales del desplazamiento forzado - modulo 6 unidad 4. En Cátedra virtual Desplazamiento forzado en Colombia. Universidad Nacional de Colombia - ACNUR - PIUC. Bogotá.

RIAÑO, Alcalá pilar (2006). El Desplazamiento Forzado Interno y los Procesos de memoria. En reflexiones Éticas y Metodológicas. Red nacional de Investigadores en Desplazamiento Forzado REDIF.

RODRÍGUEZ, Alba Nubia y Otros (2005). Desafíos éticos en la investigación y la intervención con personas en situación de desplazamiento forzado: una experiencia traumática de carácter político. En revista prospectiva $N^{o} 10$. Tema central: desplazamiento forzado. Escuela de Trabajo social y desarrollo humano, facultada de humanidades - Universidad del Valle. Cali.

FECHA DE RECEPCIÓN: agosto 22 de 2008

FECHA DE APROBACIÓN: octubre 20 de 2008 